\title{
Review
}

\section{Traumatic brain injury}

\author{
Jane E. Risdall ${ }^{1}$ and David K. Menon ${ }^{2, *}$ \\ ${ }^{1}$ Surgeon Commander, Royal Navy, UK \\ ${ }^{2}$ Division of Anaesthesia, University of Cambridge Box 93, Cambridge CB2 2QQ, UK
}

\begin{abstract}
There is an increasing incidence of military traumatic brain injury (TBI), and similar injuries are seen in civilians in war zones or terrorist incidents. Indeed, blast-induced mild TBI has been referred to as the signature injury of the conflicts in Iraq and Afghanistan. Assessment involves schemes that are common in civilcian practice but, in common with civilian TBI, takes little account of information available from modern imaging (particularly diffusion tensor magnetic resonance imaging) and emerging biomarkers. The efficient logistics of clinical care delivery in the field may have a role in optimizing outcome. Clinical care has much in common with civilian TBI, but intracranial pressure monitoring is not always available, and protocols need to be modified to take account of this. In addition, severe early oedema has led to increasing use of decompressive craniectomy, and blast TBI may be associated with a higher incidence of vasospasm and pseudoaneurysm formation. Visual and/or auditory deficits are common, and there is a significant risk of post-traumatic epilepsy. TBI is rarely an isolated finding in this setting, and persistent post-concussive symptoms are commonly associated with post-traumatic stress disorder and chronic pain, a constellation of findings that has been called the polytrauma clinical triad.
\end{abstract}

Keywords: military; traumatic brain injury; blast injury; polytrauma triad; post-traumatic epilepsy; vasospasm

\section{INTRODUCTION}

The current conflicts in Iraq and Afghanistan, and the increasing burden of terrorism across the world, have resulted in a steady increase in the number of patients seen with military and military-type injuries. The number of terrorism-related deaths has increased approximately 10 -fold over the last 10 years (figure 1) [1]; and, as of the end of June 2010, the USA had lost 5543 soldiers in Operation Iraqi Freedom and Operation Enduring Freedom [2], while the UK had lost 388 military and civilian personnel in Afghanistan [3]. These fatalities represent the tip of the iceberg. For example, in the UK figures, the number of very seriously or seriously injured individuals is broadly similar to the number of fatalities, and the number of aeromedical evacuations, which probably provide a marker of significant injury, is about 10 times the number of fatalities. Similarly, terrorism-related incidents result in approximately 10 times as many injuries as fatalities [1].

\section{PHYSICAL MECHANICS}

The mechanisms of neural injury associated with traumatic brain injury (TBI) have classically been categorized as primary (those occurring at the time of the impact) and secondary (those occurring minutes to days after the injury, and are broadly the consequence of the host response). While these are broadly similar in military and civilian TBI, the military context

*Author for correspondence.

One contribution of 20 to a Theme Issue 'Military medicine in the 21 st century: pushing the boundaries of combat casualty care'. involves two mechanical modes of injury far more commonly: penetrating ballistic injury and blast injury.

\section{(a) Penetrating trauma}

For a detailed description, the reader is referred to recent reviews on the mechanical physics and biological consequences of ballistic projectile injury $[4,5]$. In penetrating brain injury a foreign body penetrates the bony skull and passes into (and in some cases through) the substance of the brain. This leads to physical disruption of neurons, glial cells and fibre tracts. Damage may be compounded by ischaemia and haemorrhage. Penetrating ballistic injury (e.g. rifle shot) commonly results in high levels of energy transfer to the tissues. The amount of tissue damage is determined by the amount of kinetic energy (KE) lost by the projectile in the body [6]. KE is described by the equation:

$\mathrm{KE}=\frac{1}{2} m v^{2}$,

where $m$ is the mass and $v$ the velocity, so although the KE of the projectile varies linearly with weight, it increases exponentially with velocity. There are three mechanisms of tissue damage owing to bullets: laceration and crushing, shock waves and cavitation. Laceration and crushing are generated by the projectile displacing the tissues in its track. Angle of impact, yaw and tumbling of the bullet will also affect the extent of damage caused. Shock waves are generated by the compression of tissues that lie ahead of the bullet and are an effect limited to high-velocity missiles (generally exceeding 2500 feet s$^{-1}$ ). Cavitation, or cavity formation along the bullet track, 


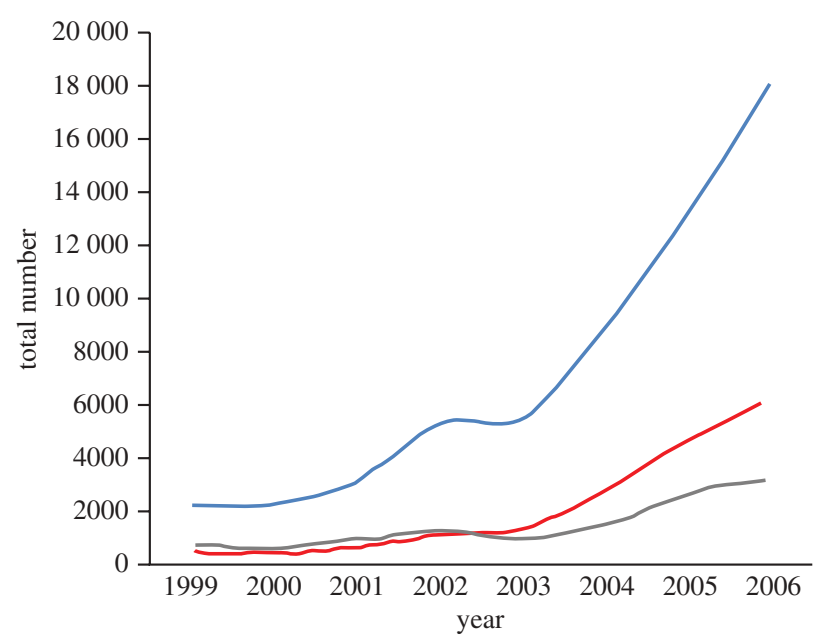

Figure 1. Worldwide trends in terrorist explosive events from 1999 to 2006. Grey line, incidents; red line, deaths; blue line, injuries.

results from the compression and acceleration of tissue in a direction forward and laterally away from the track of the bullet or other missile. A transient water vapour-filled cavity develops around the bullet and its track, which may be many times the diameter of the bullet. As the bullet passes, subatmospheric pressure enlarges the cavity, then, within a few microseconds, the cavity begins to collapse as a result of pressure and tissue recoil. The cavity reforms and collapses several more times with rapidly diminishing amplitude until all the energy has been dissipated [7]. This alternating stretch and compression of the tissues adds substantially to the tissue damage in a wound from a high-velocity missile and is particularly pertinent in penetrating brain trauma.

\section{(b) Blast injury}

This has risen to prominence in the current conflicts, and represents a specific form of primary injury, with sufficiently different physical attributes (and possibly biological consequences) to be classified separately. In brief, the mechanical insult from blast injury is classified as either primary, secondary, tertiary or quaternary. The physical characterization of blast injury has been addressed in detail in previous publications [1] and is well covered elsewhere in this special issue, and will not be discussed in detail. However, those aspects of the topic that specifically pertain to TBI are briefly discussed here. The reader looking for more details in this area is referred to excellent recent reviews on this topic $[8,9]$.

The mechanisms that are responsible for primary blast injury to the brain are being increasingly well understood. Shock tube experiments in animals confirm that blast pressures, without associated cranial impacts, can cause TBI $[10,11]$. Several mechanisms have been proposed, including bulk acceleration of the head [12], transmission of loads through orifices in the skull and compression of the thorax, which generates a vascular surge to the brain [10]. In addition, recent data [13] show that a blast wave causes the skull to dynamically deform, which creates localized regions of high and low pressure, and large pressure gradients that sweep through the brain. Even though

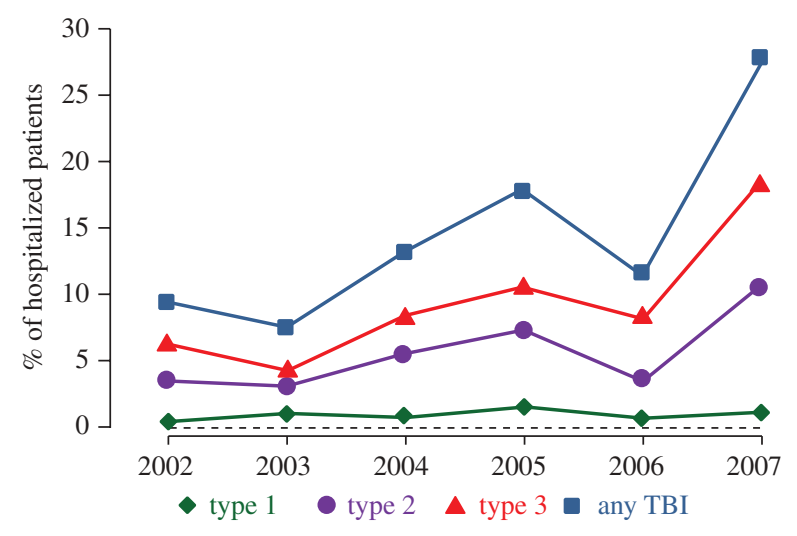

Figure 2. TBI hospitalization rates in Operation Enduring Freedom as percentages of total injury rates (redrawn from [37]). All rates expressed as per 10000 soldier-years. TBI classification by type is based on the Barell matrix [59].

the physical deformations associated with this wave are small (approx. $50 \mu \mathrm{m}$ at the skull), the loads are at least as large as those from a typical injury-inducing impact. Intriguingly, helmets affect the interaction of the blast with the head. Without padding, the clearance gap between the helmet and the head allows underwash that amplifies pressures acting directly on the skull. Padding inhibits this underwash, but can more strongly couple helmet motion to the head, increasing the mechanical loads in the brain. If localized skull flexure proves to be a primary mechanism for blast TBI, then an effective mitigation strategy would be to deny the blast wave access to the airspace under the helmet and prevent the motion and deformation of the helmet from transferring to the skull.

Secondary blast injury is caused by debris physically displaced by the blast overpressure or blast winds [1]. The resulting combination of penetrating and blunt injuries is similar to wounds seen in civilian trauma, but two points are worth noting. First, in terrorist incidents, there is a tendency for a substantial number of secondary blast injuries, since munitions usually contain fragmenting items such as ball bearings, nails, rocks or scrap metal to maximize lethality [14-16]. These can cause small (and sometimes hidden) puncture wounds. Second, these fragments travel far beyond the impact of the blast wave (up to thousands of metres) and hence secondary blast injuries are more common than primary blast injuries [17-21]. In the context of TBI, these considerations dictate the careful inspection of victims for such injury, particularly in the neck, where vascular injury may contribute to neurological deficit.

Tertiary blast injuries are caused when a person is physically displaced by the force of the peak overpressure and blast winds and sustains blunt trauma injury such as closed head injuries. Additionally, collapse of buildings or surrounding structures confers a raised risk of severe tertiary blast injury both directly by injury to the head and by causing increased secondary insults through primary crush asphyxia and the consequences of extracranial injury [22-26].

Quarternary blast injury results from thermal or chemical injuries associated with the blast; these may modulate the severity of neural insult through secondary injury mechanisms. 
Finally, there have been isolated reports of 'quiniary blast injury', in victims of terrorist blast injury [27]. These individuals exhibit an immediate hyperinflammatory state, manifested as hyperpyrexia, sweating, low central venous pressure and positive fluid balance. Unconventional materials used in the manufacture of explosive may be the cause of this phenomenon; the explosive pentaerythritoltetranitrate, which has been postulated to have nitric oxide-like effects has been implicated in this regard. However, the phenomenon may simply be the consequence of blast exposure in unprotected individuals (as opposed to professional soldiers, who usually wear body armour).

\section{PATHOPHYSIOLOGICAL MECHANISMS}

The pathophysiological mechanisms associated with military TBI are, at least in principle, very similar to those in civilian TBI, even in models of pure or predominantly blast TBI $[8,9]$. It is still customary to recognize a separation of primary injury (that is caused at the time of the physical insult) and secondary injury caused by either host cellular responses (such as excitotoxicity, oxidant injury and inflammation) or physiological insults (such as ischaemia, hypoxaemia, hypo- or hypercapnia, intracranial hypertension and hypo- or hyperglycaemia). Neuronal, axonal and glial injury have been reported [28,29], and both necrotic and apoptotic cell pathways have been implicated in neuronal loss [30,31]. Individual studies have variably described selective axonal or hippocampal vulnerability following blast injury. Two particular characteristics of blast injury have been reported, primarily in case series [32]. The first is the development of early and severe oedema, associated with substantial disruption of the blood-brain barrier. This has, in some analyses, been associated with microglial activation and upregulation of inducible nitric oxide synthase, with consequent oxidant and nitric oxide-mediated microvascular injury $[33,34]$. The second is a prominent component of major vascular injury, with substantial vasospasm [35] and late pseudoaneurysm formation. The mechanisms for this are unclear, but it has been speculated that this may be a consequence of transmission of the blast wave through the vascular tree.

\section{EPIDEMIOLOGY}

Historically, in combat-related injuries, $15-20 \%$ of injuries occur above the clavicles [36]. The estimate in recent and ongoing conflicts is similar, and a significant proportion of these injuries include TBI. TBI has been calculated as resulting in a 0.14 per cent hospital admission rate among all deployed personnel in US figures [37]. Regardless of the classification system used, soldiers with TBI appear to represent a larger proportion of US casualties in Iraq and Afghanistan compared with those in other recent conflicts. Based on head, face and neck injuries, it has been estimated that at least 22 per cent of wounded soldiers evacuated from these conflicts have TBI [38-40]. One recent medical study, using postdeployment screening tools, concluded that 12 per cent of returning soldiers had experienced injuries with loss of consciousness (LOC) [41]. An analysis of helmet use revealed that approximately 80 per cent of soldiers with TBI were wearing head protection at the time of the injury [37]. Further, the proportion of casualties with TBI is increasing year-on-year as the conflict continues (figure 2) [37]. However, data on combat TBI are not uniform between countries. TBI is consistently a major contributor to fatalities; 42 per cent of British casualties killed by hostile action in Afghanistan and Iraq between April 2006 and March 2007 had non-survivable brain injury [42], while in Somalia, 43 per cent of fatal penetrating injuries occurred to the head or neck [43]. However, the UK data suggest that it is a less significant contributor to survivable injury: during the first Gulf War, only one of 24 head injuries required craniotomy [44], and while 17 per cent of 224 cases from Afghanistan involved the head and neck, only two craniotomies and two neck explorations were required [45]. These data suggest that, in the UK experience, head injury is frequently the fatal cause of death in military trauma, but among survivors, the rate of significant head injury requiring surgical intervention is quite low.

One reason for this discordance between US and UK data may arise from the high reported incidence of mild TBI in US military personnel returning from combat $[40,46]$. Incidence of exposure to blast is high in such individuals, and blast TBI is now recognized as a specific entity within the broad spectrum of TBI. However, many soldiers only present late, and others are identified by routine (self) screening. Initially, there was an impression that the incidence of reported mild blast TBI may be substantially higher in US military personnel, compared with UK military personnel [40,47]. However, caution is needed before this statement can be accepted, since the difference may be due to different approaches to screening, definition and/or reporting. For example, one report from the USA quotes a 59 per cent incidence of blast TBI [46], while a UK paper reports an overall blast injury incidence of 3.7 per cent [48]. However, a closer examination of the two data sources shows that direct comparisons are inappropriate. The denominator for the US data are survivors of acute battlefield injuries admitted to a tertiary centre in the USA after evacuation from the theatre of war, all of whom had documented blast injury, and had a diagnosis of TBI based on comprehensive assessment. On the other hand, the UK data address acute assessment of injury severity in the theatre of war, and the denominator includes a high percentage of fatal casualties. Differences in reporting therefore need to be carefully considered and reconciled before rational comparisons are possible to confirm or exclude real differences in TBI incidence. Agreement on definitions, screening procedures and criteria for establishing a diagnosis of TBI are required to promote consistency in reporting. One advance in this area is recent agreement on definition of what constitutes a TBI, and particularly, how a diagnosis of TBI may be differentiated from other conditions that are potential differential diagnoses [48].

\section{ASSESSMENT, GRADING AND OUTCOME PREDICTION}

The assessment and grading of TBI have classically used the Glasgow coma score (GCS), described in 
1974 by Teasdale \& Jennett [49]. The summed GCS has traditionally resulted in classification of TBI into mild (GCS 14-15), moderate (GCS 9-13) or severe (GCS less than 9) categories. The GCS provided an enormous advance in quantifying the severity of TBI, and retains some predictive power for outcome across the TBI severity range in recent prognostic models of TBI outcome [50,51]. However, in the most severe patients with TBI, the combination of early pre-hospital sedation and endotracheal intubation and a tendency to rely on intracranial pressure (ICP) (rather than sedation reversal and clinical assessment) for clinical decision making have meant that the predictive power of the GCS may be severely blunted [52]. A recent authoritative workshop made a strong and plausible case for the development of more detailed systems of TBI classification that took account of the imaging advances and pathophysiological knowledge that has been acquired since the GCS was devised [53].

In terms of modifying prognosis, an additional major issue is the physiological vulnerability of patients with TBI, particularly those with moderate or severe injury. The importance of hypoxia and hypotension as key determinants of outcome was recognized by reports based on data from the Traumatic Coma Data Bank [54], and more recent reports suggest that physiological insults continue to be an issue, both in the emergency room [55] and in the critical care unit [56] context. The odds ratios for worse outcomes as a consequence of episodes of hypoxia or hypotension range between 3 and 8 in these reports. These are substantial effects, and could easily overwhelm any benefit from a new therapy. Consequently, the development of robust risk-adjustment scores by the CRASH [50] and IMPACT [51] collaborations, which incorporate these outcome determinants, is very useful [57]. However, these prediction models have been developed in civilian populations, and should be used with substantial caution in military TBI, unless there is appropriate validation. In any case, their use to predict outcome in individuals is inappropriate.

Alternative classifications of TBI that are in more common use in military contexts are based on the presence or absence of structural abnormalities, LOC, post-traumatic amnesia and the GCS. These have been used in recent US guidelines for TBI triage and management [58].

Another scheme for classification, used in some recent papers on military TBI [37], is based on the Barell Matrix [59], which combines an assessment of injury severity and site. Patients are classified as suffering a type 1 injury if they have recorded evidence of an intracranial injury, a moderate or prolonged LOC or injuries to optic nerve pathways. Type 2 injuries are characterized by no recorded evidence of intracranial injury, and LOC of less than $1 \mathrm{~h}$, or lack of evidence of (or an absence of recorded duration of) LOC. Type 3 injuries have no evidence of intracranial injury or LOC. In this grading system, type 1 injuries are clearly separated from the other two categories with a substantially higher injury severity score, mortality and median inpatient and ICU stay. However, it does not easily map to other grading schemes. It is worth noting that the scheme has been apparently validated on civilian casualties of explosions (who rarely, if ever, have protective armour), and is predicated on mortality (rather than functional outcome) as an outcome. Finally, the validation data that are commonly quoted show little discrimination between type 2 and type 3 injuries, suggesting that most patients with a broad range of significant TBI are categorized as type 1 .

\section{IMAGING AND MOLECULAR BIOMARKERS}

A biomarker is an indicator of a specific biological or disease state that is classically measured using samples taken from either the affected tissue or peripheral body fluids. More recently, this definition has been widened to include other forms of data that provide consistent markers of diagnosis, pathophysiology, disease severity, prognosis, appropriate therapy or evidence of response to therapy. In the context of TBI, much of the literature has focused on biomarkers in blood or CSF, using either conventional $[60,61]$ or novel $[62,63]$ tools. Two approaches have been adopted to detect biomarkers. The first is the quantification of specific molecules that have been suggested by knowledge of pathophysiology. For example, calpain breakdown is seen in necrotic cell death, while caspase activation is a hallmark of apoptotic cell death. Detection of calpain breakdown products or markers of caspase activation have therefore been used as biomarkers of these two processes in tissue. A second approach is data-driven, with screening of biological samples using novel high-throughput techniques for differences between patients with TBI and controls, or different severities of TBI, or different TBI outcomes. Both approaches show promise, but have not delivered on a clinically validated biomarker for any application. Biomarkers that have been investigated in TBI are listed in table 1 , and readers who wish more details are referred to a range of excellent recent review articles [60-63].

In addition to demonstrated biological validity, a biomarker is only likely to be useful in the clinical context if it can be assayed in a readily accessible biological compartment. Thus, CSF levels of a prognostic biomarker may be relatively easily accessible in severe TBI, where ventriculostomies are common. However, a biomarker targeted at the diagnosis of mild TBI will need to be detected in blood, urine or saliva. In the military context, this last area is probably the application for which biomarkers are in most demand, but thus far, there have been no clear successes in this area. There has also been increasing interest in using imaging [64], particularly magnetic resonance imaging (MRI), as a biomarker of significant TBI in the context of blast injury or multiple trauma. Diffusion tensor MRI shows particular promise in this area, but further work is required.

\section{CLINICAL MANAGEMENT ISSUES}

\section{(a) Evacuation}

Following injury, soldiers typically receive level I/role 1 (US/UK terminology) care at the site of injury. 
Table 1. Biomarkers in TBI [61-64]. NSE, neuron-specific enolase; C-tau, cleaved tau; GFAP, glial fibrillary acid protein; RBP-4, retinol-binding protein-4.

process/target

mild TBI diagnosis

differential diagnosis penetrating TBI

intracranial hypertension

blood-brain barrier leak

outcome prediction biomarkers with data in human TBI

S100B, NSE, C-tau

neuropeptide Y, dehydroepiandrosterone (DHEA); DHEA/cortisol ratio of mTBI versus PTSD high-throughput immunoblotting - several candidates from TBI models

C-tau, S100B, GFAP (also RBP-4 and ceruloplasmin from high-throughput screens)

S100B

levels of S100B, NSE, GFAP, C-tau
The use of field responses by unit members is uniform across many forces, as is an increasing trend to ensure rapid early evacuation (typically by helicopter) [65-67]. There are differences in the composition of evacuation teams between the forces of different countries. For example, the UK medical evacuation response teams typically have an anaesthetist or emergency medicine physician on board helicopters that undertake medical evacuation from the site of injury [65]. While the presence of specialist clinical expertise might be thought to offer an advantage, there have been no formal comparisons of this model with systems that are based on paramedic care during evacuation.

Injured combatants are airlifted from injury sites to level II/role 2 facilities, which include plain radiography, full resuscitation and operative facilities, but no specialist neurosurgical care. While there have been discussions (and training schemes) to facilitate the delivery of lifesaving neurosurgical interventions by non-neurosurgeons, this is not a currently implemented option. Where indicated, and where clinical condition permits, patients are transferred to level III/role 3 facilities, which offer the first opportunity for neuroimaging with X-ray-computed tomography (X-ray CT) and access to specialist neurosurgical care. The availability of ICP monitoring is, in principle, available at level III centres, commonly through a ventriculostomy, allowing adoption of conventional ICP-/cerebral-perfusion-pressure-based clinical protocols. The common occurrence of severe and early cerebral oedema has led to increasing use of decompressive craniectomy.

The aim of interventions at this stage is to stabilize patients for transfer back to a base facility with full acute diagnostic and therapeutic capability. Such transfer is accomplished by a specialist team, termed a critical care air transport team in US parlance and critical care air support teams in UK parlance $[66,67]$. These are semi-elective transfers of stabilized patients who, as a minimum, have a secure airway, haemorrhage control and extremity fractures immobilized. Radiographic clearance of spinal injuries may have been undertaken. However, where doubt exists, cervical immobilization by collars is maintained, and the thoracic and lumbar spine is treated as unstable during transfer. Full general ICU monitoring and blood gas measurement are usually available during such transfers, but ICP monitoring is not universal. Where ventriculostomies are in place, ICP can be monitored during transit. However, to date, no commercially available microtransducers have been assessed as safe and reliable for use in flight by the Royal Air Force, so early continuous ICP monitoring may only be available for military patients who have undergone neurosurgical intervention and have a ventriculostomy in place. Descriptions of clinical transfer protocols in the literature (e.g. sedation, gastric acid protection and thromboprophylaxis) are very similar to those used for civilian TBI transfers. The stresses of aeromedical transfer, including reductions in ambient oxygen partial pressures, vibration and the accelerative and deceleration effects of take-off and landing, can all contribute to haemodynamic instability and ICP elevation. It has been suggested, based on animal data, that these stresses may contribute to 'second hit' that worsens neuroinflammation in such settings [68]. Although results of formal systematic studies are currently unavailable, clinical experience suggests that peak ICP elevation may occur 3-5 days post-injury, and caution is exercised about transfer at this stage. However, hard clinical data to support a rational decision regarding the timing of safe transfer in such patients are unavailable.

\section{(b) Telemedicine}

The limited resources at forward operational sites have led to an increased effort to use telemedicine for a variety of purposes in the combat setting [69]. This includes electronic cognitive assessment systems to identify concussion and mild TBI in soldiers after blast injury. Such remote assessment can involve web-based applications, laptop computers and/or hand-held data management devices. Early identification of mild TBI in this way can facilitate safe and efficient triage, and support decisions regarding evacuation or return to active duty. Acute and subacute care of injured soldiers can be supported by video teleconferencing and sharing of electronic medical record with TBI experts (sometimes during the conduct of surgical interventions). Such interactions also contribute to continuity of care, by making clinical experts at base hospitals involved in early care, and hence fully conversant with the details of management in individual patients. Telemedicine can also be used for rehabilitation, and to support home care, but this discussion is outwith the focus of the current article. It is relevant to note that such approaches can not only optimize care in individual patients, but also support staff training. 


\section{CLINICAL PROTOCOLS FOR CRITICAL CARE IN MODERATE AND SEVERE TRAUMATIC BRAIN INJURY}

The principles of care of critically ill patients with moderate and severe TBI in the military context are broadly similar to those used in civilian TBI [70]. However, ICP monitoring may be unavailable in many patients, especially those who have not had operative neurosurgical intervention. Consequently, algorithms of clinical care based on ICP monitoring may need to be substantially modified. Broad strategic decisions regarding the safety of transfer may need to be made based on CT scan appearance, but these may be misleading if undertaken early in the clinical course, before ICP elevations have had a chance to declare themselves. These uncertainties have led to a search for other options that will allow an assessment of ICP in the field setting. However, no entirely satisfactory non-invasive techniques have yet been developed to monitor ICP when invasive methods are not available. Tympanic membrane displacement [71], ultrasound 'time of flight' [72] and transcranial Doppler techniques [73] have all been described, but none has gained widespread acceptance, since they provide indirect or derived values and are operator dependent. More recently, techniques using ocular ultrasound to measure the diameter of the optic nerve sheath have been described [74,75]. Values above a threshold of $5.2 \mathrm{~mm}$ appear to correlate well with directly measured raised ICP values above $20 \mathrm{mmHg}$ and changes in ICP are reflected in changes in optic nerve sheath diameter [76]. This technique provides the possibility of identifying patients at risk of raised ICP prior to aeromedical evacuation and allows their management to be tailored accordingly.

\section{SURGERY AND INTERVENTIONAL NEURORADIOLOGY}

While the general principles of surgical management in military TBI are similar to civilian trauma, some issues merit special attention.

\section{(a) Decompressive craniectomy}

There is an increasing clinical recognition that victims of penetrating ballistic injury and closed blast injury often suffer early and severe oedema of both extraand intracranial tissue, and that such oedema can lead to early and life-threatening ICP elevation $[77,78]$. This is coupled with a need to safely transfer soldiers away from the theatre of war on long aeromedical transfers (sometimes without ICP monitoring); and local civilians to indigenous hospitals where facilities are limited, and ongoing specialist critical care for ICP management is unavailable. These considerations have led neurosurgeons to undertake early decompressive craniectomy as a means of rapidly achieving definitive and sustained ICP control, with an increasing tendency to maximize bony decompression while minimizing brain debridement. In this setting, the availability of CT angiography has proved an excellent diagnostic aid since significant cerebrovascular injury is seen in approximately 30 per cent of this patient population. Where major intracranial vascular injury was suspected or established, the neck was commonly exposed to allow proximal vascular control if required. Other key lessons based on this experience include the use of 'T-bar' scalp incisions; the need to keep operation times and blood loss to a minimum to mitigate effects on coagulation and haemodynamic stability, and to minimize the need for scarce blood component therapy; decompression of the squamous temporal bone and sphenoid wing (along with a temporal tip lobectomy in some cases) to allow for temporal lobe swelling; and ensuring that the operative technique facilitated subsequent cranioplasty.

\section{(b) Neurovascular injury}

Recent wartime experience in the Iran-Iraq war and current conflicts have substantially increased the literature experience of cerebrovascular injury, including dissection, arteriovenous fistulae and traumatic aneurysms [35,79]. There is also an increasing recognition of the incidence and significance of post-traumatic vasospasm. As judged by trends in transcranial Doppler blood flow velocities, vasospasm seemed to appear at 5-7 days post-injury, and peak at 14 days post-injury. Initial impressions were that vasospasm may be more common in the context of blast injury, but it has not been possible to confirm this. However, vasospasm is significantly associated with the presence of haemorrhage, pseudoaneurysm formation and the number of brain lobes injured. It is also a marker of increased mortality, poor functional outcome and increased resource utilization. Aggressive surgical management may improve outcome, and endovascular treatment with angioplasty can result in improvements in vasospasm.

\section{ASSOCIATED MORBIDITY, LATE SEQUELAE AND DIFFERENTIAL DIAGNOSIS}

\section{(a) Visual and auditory deficits}

Visual and auditory deficits are thought to be particularly common with blast injury [80]. In a study of 62 patients with blast-related TBI admitted to a US rehabilitation centre, hearing impairment was seen in 19 per cent of patients, visual impairment in 34 per cent and both (dual sensory impairment (DSI)) in 32 per cent. Only 15 per cent of the patients had no visual or auditory impairment. Multiple sensory deficits have a substantial impact on the clinical course of these patients: regression analyses demonstrated that DSI significantly contributed to reduced rehabilitation gains as measured by changes in functional independence measure scores.

\section{(b) Post-traumatic epilepsy}

Post-traumatic epilepsy (PTE) may represent another major late morbidity in this population [81]. PTE usually develops within five years of head injury, with a risk estimated at 53 per cent risk in penetrating TBI, between 10 and 25 per cent in combat-associated closed-head trauma with positive brain imaging and about 5 per cent in moderately severe closedhead injury with normal CT imaging. However, the impact of mild TBI associated with blast exposure 


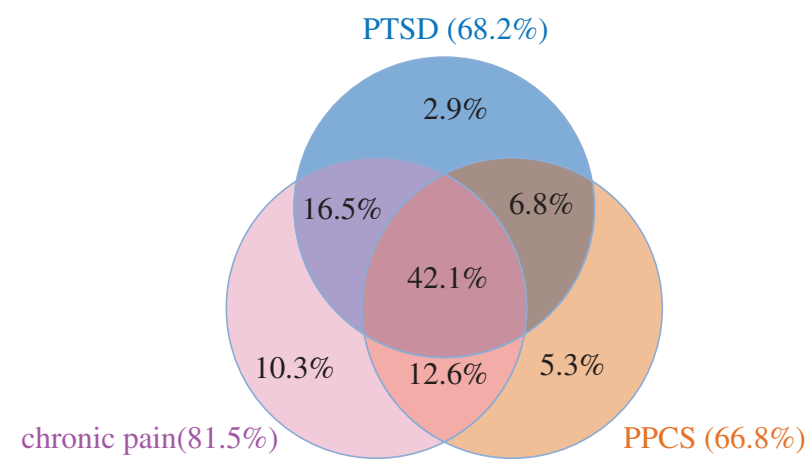

Figure 3. The 'polytrauma clinical triad' in $\mathrm{OEF} / \mathrm{OIF}$ veterans: incidence of post traumatic stress disorder (PTSD), persistent post-concussive systems (PPCS), and chronic pain in 340 veterans of Operation Enduring Freedom and Operation Iraqi Freedom evaluated at a polytrauma network site in the USA. Only 12 of the 340 veterans were free of all three symptoms. Of the remainder, very few had only symptoms from one of the components of the triad, and $42 \%$ had symptoms referable to all three components of the triad. Figure redrawn from data in [90].

on the incidence of late PTE remains unclear. In a sobering analysis, Chen et al. [81] estimated that approximately 0.5 per cent of the entire population of deployed US troops in recent conflicts were likely to develop PTE. Given that the total deployment of US troops in these conflicts exceeds two million, this implies 10000 new cases of PTE in the USA as a consequence.

\section{(c) Mild traumatic brain injury and} post-traumatic stress disorder

Mild TBI associated with blast injury [40,56] has been described as the 'signature injury' of the Iraq and Afghanistan conflicts. A seminal paper from Hogue et al. [46] recorded that of 2525 returning US infantrymen, 4.9 per cent reported injuries with LOC, 10.3 per cent with altered mental status and 17.2 per cent with no change in neurological function. Of the soldiers reporting injuries with an LOC, 43.9 per cent met criteria for post-traumatic stress disorder (PTSD), while this diagnosis was only established in 27.3 per cent of those with altered mental status, 16.2 per cent of injured soldiers with no neurological symptoms and 9.1 per cent of non-injured soldiers. Mild TBI (as diagnosed by a history of LOC) was associated with poor general health, missed workdays, increased access to medical care and somatic and post-concussive symptoms. Several points are worth noting. These associations disappeared when the comparisons were adjusted for PTSD and depression. These data are important for several reasons. First, the high incidence of PTSD in the non-injured majority speaks to the substantial psychological morbidity seen in this population, which is covered elsewhere in this issue. However, they also address the close interaction between 'psychological' morbidity and a 'physical' diagnosis of mild TBI. Surprisingly, the mechanism (emotional versus biomechanical) and locus (head versus other regions) of injury are weak determinants of whether an individual develops PTSD, persistent post-concussive symptoms or both
[82]. The most important determinant of the risk of developing both conditions may be reduced cognitive reserve (either pre-morbid, or related to recent mechanical or psychological trauma) [82]. The overlap between the two conditions is further supported by reduction in hippocampal volume, detected by MRI, not only in patients with TBI, but also in patients with PTSD [83-85]. An additional late finding in TBI in general, and returning combatants in particular, is the presence of chronic pain (particularly headache) [86-89], which overlaps in its incidence with PTSD and mild TBI/post-concussive symptomatology (figure 3). Indeed, these associations have been formalized as a triad in official guidelines that deal with the management of such patients [58].

This discussion emphasizes the artificiality of any dichotomy between neurological and psychiatric morbidity in TBI as a whole, and military TBI in particular. It is essential that both epidemiological and interventional studies recognize the close association between these areas of morbidity as markers of common pathophysiology, inter-related outcomes and therapy targets.

\section{REFERENCES}

1 Wolf, S. J., Bebarta, V. S., Bonnett, C. J., Pons, P. T. \& Cantrill, S. V. 2009 Blast injuries. Lancet 374, 405-415. (doi:10.1016/S0140-6736(09)60257-9)

2 See http://www.defense.gov/news/casualty.pdf.

3 See http://www.dasa.mod.uk/applications/newWeb/www/ index.php?page $=48 \&$ thiscontent $=1360 \&$ date $=2010-06-$ 15\&pubType $=0 \&$ Publish Time $=09: 30: 00 \&$ from $=$ home $\&$ tabOption $=1$.

4 Maiden, N. 2009 Ballistics reviews: mechanisms of bullet wound trauma. Forensic Sci. Med. Pathol. 5, 204-209. (doi:10.1007/s12024-009-9096-6)

5 Jandial, R., Reichwage, B., Levy, M., Duenas, V. \& Sturdivan, L. 2008 Ballistics for the neurosurgeon. Neurosurgery 62, 472-480. (doi:10.1227/01.neu.000031 $6015.05550 .7 \mathrm{a})$

6 Crockard, H. A. 1974 Bullet injuries of the brain. Ann. R. Coll. Surg. Engl. 55, 111-123.

7 Swan, K. G. \& Swan, R. C. 1984 Man's best friend or man? Physiologist 27, 347-350.

8 Cernak, I. \& Noble-Haeusslein, L. J. 2010 Traumatic brain injury: an overview of pathobiology with emphasis on military populations. F. Cereb. Blood Flow Metab. 30, 255-266. (doi:10.1038/jcbfm.2009.203)

9 Hicks, R. R., Fertig, S. J., Desrocher, R. E., Koroshetz, W. J. \& Pancrazio, J. J. 2010 Neurological effects of blast injury. F. Trauma 68, 1257-1263. (doi:10.1097/ TA.0b013e3181d8956d)

10 Cernak, I., Wang, Z., Jiang, J., Bian, X. \& Savic, J. 2001 Ultrastructural and functional characteristics of blast injury-induced neurotrauma. f. Trauma 50, 695-706. (doi:10.1097/00005373-200104000-00017)

11 Suneson, A., Hansson, H. A. \& Seeman, T. 1990 Pressure wave injuries to the nervous system caused by high-energy missile extremity impact: Part II. Distant effects on the central nervous system - a light and electron microscopic study on pigs. F. Trauma 30, 295-306. (doi:10.1097/ 00005373-199003000-00007)

12 Stuhmiller, J. H. 2008 Blast injury: translating research into operational medicine. In Quantitative physiology and concepts in military operational medicine. Textbook of military medicine 
(eds W. R. Santee \& K. E. Friedl). Bethesda, MD: Borden Institute, US Army Medical Department.

13 Moss, W. C., King, M. J. \& Blackman, E. G. 2009 Skull flexure from blast waves: a mechanism for brain injury with implications for helmet design. Phys. Rev. Lett. 103, 108702. (doi:10.1103/PhysRevLett.103.108702)

14 de Ceballos, J. P., Turegano-Fuentes, F., Perez-Diaz, D., Sanz-Sanchez, M., Martin-Llorente, C. \& Guerrero-Sanz, J. E. 200511 March 2004: the terrorist bomb explosions in Madrid, Spain - an analysis of the logistics, injuries sustained and clinical management of casualties treated at the closest hospital. Crit. Care 9(Suppl. 1), 104-111.

15 Kluger, Y. 2003 Bomb explosions in acts of terrorismdetonation, wound ballistics, triage and medical concerns. Isr. Med. Assoc. F. 5, 235-240.

16 Kluger, Y., Kashuk, J. \& Mayo, A. 2004 Terror bombingmechanisms, consequences and implications. Scand. 7. Surg. 93, 11-14.

17 Aharonson-Daniel, L., Klein, Y. \& Peleg, K. 2006 Suicide bombers form a new injury profile. Ann. Surg. 244, 1018-1023. (doi:10.1097/01.sla.0000225355.06362.0f)

18 Alfici, R., Ashkenazi, I. \& Kessel, B. 2006 Management of victims in a mass casualty incident caused by a terrorist bombing: treatment algorithms for stable, unstable, and in extremis victims. Mil. Med. 171, 1155-1162.

19 Garner, M. J. \& Brett, S. J. 2007 Mechanisms of injury by explosive devices. Anesthesiol. Clin. 25, 147-160.

20 Mellor, S. G. \& Cooper, G. J. 1989 Analysis of 828 servicemen killed or injured by explosion in Northern Ireland 1970-84: the hostile action casualty system. Br. F. Surg. 76, 1006-1010. (doi:10.1002/bjs.1800761006)

21 Sebesta, J. 2006 Special lessons learned from Iraq. Surg. Clin. North Am. 86, 711-726. (doi:10.1016/j.suc.2006. 03.002)

22 Arnold, J. L., Tsai, M. C., Halpern, P., Smithline, H., Stok, E. \& Ersoy, G. 2003 Mass-casualty, terrorist bombings: epidemiological outcomes, resource utilization, and time course of emergency needs (part I). Prehosp. Disaster Med. 18, 220-234.

23 Halpern, P., Tsai, M. C., Arnold, J. L., Stok, E. \& Ersoy, G. 2003 Mass-casualty, terrorist bombings: implications for emergency department and hospital emergency response (part II). Prehosp. Disaster Med. 18, 235-241.

24 Arnold, J. L., Halpern, P., Tsai, M. C. \& Smithline, H. 2004 Mass casualty terrorist bombings: a comparison of outcomes by bombing type. Ann. Emerg. Med. 43, 263-273. (doi:10.1016/S0196-0644(03)00723-6)

25 Frykberg, E. R., Hutton, P. M. \& Balzer Jr, R. H. 1987 Disaster in Beirut: an application of mass casualty principles. Mil. Med. 152, 563-566.

26 Hogan, D. E., Waeckerle, J. F., Dire, D. J. \& Lillibridge, S. R. 1999 Emergency department impact of the Oklahoma city terrorist bombing. Ann. Emerg. Med. 34, 160-167. (doi:10.1016/S0196-0644(99)70224-6)

27 Kluger, Y., Nimrod, A., Biderman, P., Mayo, A. \& Sorkin, P. 2007 The quinary pattern of blast injury. Am. F. Disaster Med. 2, 21-25.

28 Bauman, R. A. et al. 2009 An introductory characterization of a combat-casualty-care relevant swine model of closed head injury resulting from exposure to explosive blast. F. Neurotrauma 26, 841-860. (doi:10.1089/neu. 2008.0898)

29 Cernak, I., Wang, Z. G., Jiang, J. X., Bian, X. W. \& Savic, J. 2001 Cognitive deficits following blast injury-induced neurotrauma: possible involvement of nitric oxide. Brain Inj. 15, 593-612. (doi:10.1080/02699050010009559)

30 Cernak, I., Stoica, B., Byrnes, K. R., Di Giovanni, S. \& Faden, A. I. 2005 Role of the cell cycle in the pathobiology of central nervous system trauma. Cell Cycle 4, 1286-1293. (doi:10.4161/cc.4.9.1996)
31 Kato, K., Fujimura, M., Nakagawa, A., Saito, A., Ohki, T., Takayama, K. \& Tominaga, T. 2007 Pressuredependent effect of shock waves on rat brain: induction of neuronal apoptosis mediated by a caspase-dependent pathway. F. Neurosurg. 106, 667-676.

32 Ling, G., Bandak, F., Armonda, R., Grant, G. \& Ecklund, J. 2009 Explosive blast neurotrauma. $\mathcal{F}$. Neurotrauma 26, 815-825. (doi:10.1089/neu.2007. 0484)

33 Kaur, C., Singh, J., Lim, M. K., Ng, B. L., Yap, E. P. H. \& Ling, E. A. 1995 The response of neurons and microglia to blast injury in the rat brain. Neuropathol. Appl. Neurobiol. 2, 369-377.

34 Kaur, C., Singh, J., Moochhala, S., Lim, M. K., Lu, J. \& Ling, E. A. 1999 Induction of NADPH diaphorase nitric oxide synthase in the spinal cord motor neurons of rats following a single and multiple non-penetrative blasts. Histol. Histopathol. 14, 417-425.

35 Armonda, R. A., Bell, R. S., Vo, A. H., Ling, G., DeGraba, T. J., Crandall, B., Ecklund, J. \& Campbell, W. W. 2006 Wartime traumatic cerebral vasospasm: recent review of combat casualties. Neurosurgery 59, 1215-1225.

36 Champion, H. R., Bellamy, R. F., Roberts, P. \& Leppaniemi, A. 2003 A profile of combat injury. 7. Trauma 54, S13-S19.

37 Wojcik, B. E., Stein, C. R., Bagg, K., Humphrey, R. J. \& Orosco, J. 2010 Traumatic brain injury hospitalizations of US army soldiers deployed to Afghanistan and Iraq. Am. F. Prev. Med. 38(Suppl. 1), S108-S116.

38 Army Medical Surveillance Activity 2007 Traumatic brain injury among members of active components, US Armed Forces, 1997-2006. Med. Surveill. Mon. Rep. 14, 2-6.

39 Warden, D. L. 2006 Military TBI during the Iraq and Afghanistan wars. F. Head Trauma Rehabil. 21, 398-402. (doi:10.1097/00001199-200609000-00004)

40 Okie, S. 2005 Traumatic brain injury in the war zone. N. Engl. f. Med. 352, 2043-2047. (doi:10.1056/ NEJMp058102)

41 Schneiderman, A. I., Braver, E. R. \& Kang, H. K. 2008 Understanding sequelae of injury mechanisms and mild traumatic brain injury incurred during the conflicts in Iraq and Afghanistan: persistent postconcussive symptoms and posttraumatic stress disorder. Am. F. Epidemiol. 167, 1446-1452. (doi:10.1093/aje/kwn068)

42 Hodgetts, T. et al. 2007 Operational mortality of UK service personnel in Iraq and Afghanistan: A one year analysis 2006-2007. F. R. Army Med. Corps 153, 252-254.

43 Mabry, R. L., Holcomb, J. B., Baker, A. M., Cloonan, C. C., Uhorchak, J. M., Perkins, D. E., Canfield, A. J. \& Hagmann, J. H. 2000 United States Army Rangers in Somalia: an analysis of combat casualties on an urban battlefield. f. Trauma 49, 515-528. (doi:10.1097/ 00005373-200009000-00021)

44 Carey, M. E., Joseph, A. S., Morris, W. J., McDonnell, D. E., Rengachary, S. S., Smythies, C., Williams II, J. P. \& Zimba, F. A. 1998 Brain wounds and their treatment in VII corps during Operation Desert Storm, February 20 to April 15, 1991. Mil. Med. 163, 581-586.

45 Peoples, G. E., Gerlingher, T., Craig, R. \& Burlingham, B. 2005 Combat casualties in Afghanistan cared for by a single forward surgical team during the initial phases of Operation Enduring Freedom. Mil. Med. 170, 462-468.

46 Hoge, C. W., McGurk, D., Thomas, J. L., Cox, A. L., Engel, C. C. \& Castro, C. A. 2008 Mild traumatic brain injury in US Soldiers returning from Iraq. N. Engl. f. Med. 358, 453-463. (doi:10.1056/NEJMoa072972)

47 Ramasamy, A., Harrison, S. E., Clasper, J. C. \& Stewart, M. P. M. 2008 Injuries from roadside improvised 
explosive devices. F. Trauma 65, 910-914. (doi:10.1097/ TA.0b013e3181848cf6)

48 Menon, D. K., Schwab, K., Wright, D. W. \& Maas, A. I. R. 2010 Position statement: definition of traumatic brain injury. Arch. Phys. Med. Rehabil.

49 Teasdale, G. \& Jennett, B. 1974 Assessment of coma and impaired consciousness. A practical scale. Lancet 2, 81-84. (doi:10.1016/S0140-6736(74)91639-0)

50 MRC CRASH Trial Collaborators. 2008 Predicting outcome after traumatic brain injury: practical prognostic models based on large cohort of international patients. Brit. Med. f. 336, 425-429. (doi:10.1136/bmj.39461. 643438.25)

51 Steyerberg, E. W. et al. 2008 Predicting outcome after traumatic brain injury: development and international validation of prognostic scores based on admission characteristics. PLoS Med. 5, e165. (doi:10.1371/ journal.pmed.0050165)

52 Czosnyka, M., Balestreri, M., Steiner, L., Smielewski, P., Hutchinson, P. J., Matta, B. \& Pickard, J. D. 2005 Age, intracranial pressure, autoregulation, and outcome after brain trauma. F. Neurosurg. 102, 450-454. (doi:10. 3171/jns.2005.102.3.0450)

53 Saatman, K. E., Duhaime, A. C., Bullock, R., Maas, A. I., Valadka, A., Manley, G. T. \& Workshop Scientific Team and Advisory Panel Members. 2008 Classification of traumatic brain injury for targeted therapies. $\mathcal{F}$. Neurotrauma 25, 719-738. (doi:10.1089/neu.2008.0586)

54 Chesnut, R. M., Marshall, L. F., Klauber, M. R., Blunt, B. A., Baldwin, N., Eisenberg, H. M., Jane, J. A., Marmarou, A. \& Foulkes, M. A. 1993 The role of secondary brain injury in determining outcome from severe head injury. F. Trauma 34, 216-222. (doi:10. 1097/00005373-199302000-00006)

55 Manley, G., Knudson, M. M., Morabito, D., Damron, S., Erickson, V. \& Pitts, L. 2001 Hypotension, hypoxia, and head injury: frequency, duration, and consequences. Arch. Surg. 136, 1118-1123.

56 Hlatky, R., Contant, C. F., Diaz-Marchan, P., Valadka, A. B. \& Robertson, C. S. 2004 Significance of a reduced cerebral blood flow during the first 12 hours after traumatic brain injury. Neurocrit. Care 1, 69-83. (doi:10.1385/NCC:1:1:69)

57 Menon, D. K. \& Zahed, C. 2009 Prediction of outcome in severe traumatic brain injury. Curr. Opin. Crit. Care 15, 437-441. (doi:10.1097/MCC.0b013e3283307a26)

58 The Management of Concussion/mTBI Working Group. 2009 VA/DoD Clinical practice guideline for management of concussion/mild traumatic brain injury. F. Rehab. Res. Develop. 4, CP1 (http://www.rehab.research. va.gov/jour/09/46/6/pdf/cpg.pdf).

59 Barell, V., Aharonson-Daniel, L., Fingerhut, L. A., Mackenzie, E. J., Ziv, A., Boyko, V., Abargel, A., Avitzour, M. \& Heruti, R. 2002 An introduction to the Barell body region by nature of injury diagnosis matrix. Inj. Prev. 8, 91-96. (doi:10.1136/ip.8.2.91)

60 Dash, P. K., Zhao, J., Hergenroeder, G. \& Moore, A. N. 2010 Biomarkers for the diagnosis, prognosis, and evaluation of treatment efficacy for traumatic brain injury. Neurotherapeutics 7, 100-114. (doi:10.1016/j. nurt.2009.10.019)

61 Kövesdi, E. et al. 2010 Update on protein biomarkers in traumatic brain injury with emphasis on clinical use in adults and pediatrics. Acta. Neurochir. (Wien) 152, 1-17. (doi:10.1007/s00701-009-0463-6)

62 Svetlov, S. I., Larner, S. F., Kirk, D. R., Atkinson, J., Hayes, R. L. \& Wang, K. K. 2009 Biomarkers of blastinduced neurotrauma: profiling molecular and cellular mechanisms of blast brain injury. F. Neurotrauma 26, 913-921. (doi:10.1089/neu.2008.0609)
63 Agoston, D. V., Gyorgy, A., Eidelman, O. \& Pollard, H. B. 2009 Proteomic biomarkers for blast neurotrauma: targeting cerebral edema, inflammation, and neuronal death cascades. F. Neurotrauma 26, 901-911. (doi:10. 1089/neu.2008.0724)

64 Van Boven, R. W. et al. 2009 Advances in neuroimaging of traumatic brain injury and posttraumatic stress disorder. F. Rehabil. Res. Dev. 46, 717-757. (doi:10. 1682/JRRD.2008.12.0161)

65 See http:/helmandblog.blogspot.com/2010/06/surgeongeneral-outlines-medical.html.

66 See http://www.mod.uk/defenceinternet/factsheets/operationsfactsheets/operationsinafghanistanbritishcasualties.htm.

67 Fang, R., Dorlac, G. R., Allan, P. F. \& Dorlac, W. C. 2010 Intercontinental aeromedical evacuation of patients with traumatic brain injuries during Operations Iraqi Freedom and Enduring Freedom. Neurosurg. Focus 28, E11.

68 Goodman, M. D., Makley, A. T., Lentsch, A. B., Barnes, S. L., Dorlac, G. R., Dorlac, W. C., Johannigman, J. A. \& Pritts, T. A. 2009 Traumatic brain injury and aeromedical evacuation: when is the brain fit to fly? f. Surg. Res. (doi:10.1016/j.jss.2009.07.040)

69 Girard, P. 2007 Military and VA telemedicine systems for patients with traumatic brain injury. F. Rehabil. Res. Dev. 44, 1017-1026. (doi:10.1682/JRRD.2006.12.0174)

70 Guidelines for the management of severe traumatic brain injury. 2007 F. Neurotrauma 24(Suppl. 1), S1-S106.

71 Shimbles, S., Dodd, C., Banister, K., Mendelow, A. D. \& Chambers, I. R. 2005 Clinical comparison of tympanic membrane displacement with invasive ICP measurements. Acta Neurochir. Suppl. 95, 197-199. (doi:10. 1007/3-211-32318-X_41)

72 Petkus, V., Ragauskas, A. \& Jurkonis, R. 2002 Investigation of intracranial media ultrasonic monitoring model. Ultrasonics 40, 829-833. (doi:10.1016/S0041624X(02)00216-0)

73 Schmidt, B., Czosnyka, M., Raabe, A., Yahya, H., Shwarze, J. J., Sackerer, D., Sander, D. \& Klingelhofer, J. 2003 Adaptive noninvasive assessment of intracranial pressure and cerebral autoregulation. Stroke 34, 84-89. (doi:10.1161/01.STR.0000047849.01376.AE)

74 Geeraets, T., Merceron, S., Bechamou, D., Vigue, B. \& Duranteau, J. 2008 Non-invasive assessment of intracranial pressure using ocular sonography in neurocritical care patients. Intensive Care Med. 34, 2062-2067.

75 Kimberley, H. H., Shah, S., Marill, K. \& Noble, V. 2008 Correlation of optic nerve sheath diameter with direct measurement of intracranial pressure. Acad. Emerg. Med. 15, 201-204.

76 Moretti, R., Pizzi, B., Cassini, F. \& Vivaldi, N. 2009 Reliability of optic nerve ultrasound for the evaluation of patients with spontaneous intracranial hemorrhage. Neurocrit. Care 11, 406-410. (doi:10.1007/s12028-0099250-8)

77 Ragel, B. T., Klimo Jr, P., Martin, J. E., Teff, R. J., Bakken, H. E. \& Armonda, R. A. 2010 Wartime decompressive craniectomy: technique and lessons learned. Neurosurg. Focus 28, E2.

78 Bell, R. S. et al. 2010 Early decompressive craniectomy for severe penetrating and closed head injury during wartime. Neurosurg. Focus 28, E1.

79 Amirjamshidi, A., Rahmat, H. \& Abbassioun, K. 1996 Traumatic aneurysms and arteriovenous fistulas of intracranial vessels associated with penetrating head injuries occurring during war: principles and pitfalls in diagnosis and management. A survey of 31 cases and review of the literature. F. Neurosurg. 84, 769-780.

80 Lew, H. L., Garvert, D. W., Pogoda, T. K., Hsu, P. T., Devine, J. M., White, D. K., Myers, P. J. \& Goodrich, 
G. L. 2009 Auditory and visual impairments in patients with blast-related traumatic brain injury: effect of dual sensory impairment on functional independence measure. F. Rehabil. Res. Dev. 46, 819-826. (doi:10. 1682/JRRD.2008.09.0129)

81 Chen, J. W., Ruff, R. L., Eavey, R. \& Wasterlain, C. G. 2009 Posttraumatic epilepsy and treatment. F. Rehabil. Res. Dev. 46, 685-696. (doi:10.1682/JRRD.2008.09. 0130)

82 Stein, M. B. \& McAllister, T. W. 2009 Exploring the convergence of posttraumatic stress disorder and mild traumatic brain injury. Am. F. Psychol. 166, 768-776. (doi:10.1176/appi.ajp.2009.08101604)

83 Di Stefano, G., Bachevalier, J., Levin, H. S., Song, J. X., Scheibel, R. S. \& Fletcher, J. M. 2000 Volume of focal brain lesions and hippocampal formation in relation to memory function after closed head injury in children. 7. Neurol. Neurosurg. Psychiatry 69, 210-216. (doi:10. 1136/jnnp.69.2.210)

84 Geuze, E., Vermetten, E. \& Bremner, J. D. 2005 MRbased in vivo hippocampal volumetrics: 2 . Findings in neuropsychiatric disorders. Mol. Psychiatry 10, 160-184. (doi:10.1038/sj.mp.4001579)

85 Jorge, R. E., Acion, L., Starkstein, S. E. \& Magnotta, V. 2007 Hippocampal volume and mood disorders after traumatic brain injury. Biol. Psychiatry 62, 332-338. (doi:10.1016/j.biopsych.2006.07.024)
86 Nampiaparampil, D. E. 2008 Prevalence of chronic pain after traumatic brain injury: a systematic review. F. $\mathrm{Am}$. Med. Assoc. 300, 711-719. (doi:10.1001/jama.300.6. 711)

87 Dobscha, S. K., Clark, M. E., Morasco, B. J., Freeman, M., Campbell, R. \& Helfand, M. 2009 Systematic review of the literature on pain in patients with polytrauma including traumatic brain injury. Pain Med. 10, 1200-1217. (doi:10. 1111/j.1526-4637.2009.00721.x)

88 Gironda, R. J., Clark, M. E., Ruff, R. L., Chait, S., Craine, M., Walker, R. \& Scholten, J. 2009 Traumatic brain injury, polytrauma, and pain: challenges and treatment strategies for the polytrauma rehabilitation. Rehabil. Psychol. 54, 247-258. (doi:10.1037/ a0016906)

89 Ruff, R. L., Ruff, S. S. \& Wang, X. F. 2008 Headaches among Operation Iraqi Freedom/Operation Enduring Freedom veterans with mild traumatic brain injury associated with exposures to explosions. F. Rehabil. Res. Dev. 45, 941-952. (doi:10.1682/JRRD. 2008.02.0028)

90 Lew, H. L., Otis, J. D., Tun, C., Kerns, R. D., Clark, M. E. \& Cifu, D. X. 2009 Prevalence of chronic pain, posttraumatic stress disorder, and persistent postconcussive symptoms in $\mathrm{OIF} / \mathrm{OEF}$ veterans: polytrauma clinical triad. F. Rehabil. Res. Dev. 46, 697-702. (doi:10.1682/ JRRD.2009.01.0006) 